\title{
Advanced Geomechanical Earth Model for Predicting Wellbore Stability and Fracking Potential
}

\author{
Rehan Ali Mohammed, Syedalireza Khatibi, Mehdi Ostadhassan, Azadeh Aghajanpour, and Alan \\ Alexeyev
}

\begin{abstract}
Minimizing the costs and risks of drilling and achieving a maximum production rate in tight shale formations is technically and economically challenging. An in-depth investigation of the Geomechanical behavior of the reservoir, including rock elastic and strength properties, and the in-situ stresses, which leads to Mechanical Earth Model (MEM), is inevitable.

In this paper, a new concept of estimating fracturing potential by Fracture Mechanical Earth Model (FMEM) is presented. We analyzed the state of In-situ stresses, formation Properties, and type of instabilities that occur around the trajectory of the wellbore by acquiring anisotropic poroelastic relationships to incorporate pore pressure and stresses changes in the field more accurately. In the next step, we determined safe mud weight window to avoid shear and tensile failure during drilling and mitigating other wellbore instabilities issues by controlling the sub surface parameters. Frack-ability, brittleness, and ductility of rock are formation stress dependent which varies from region to region, not all the rocks respond in the same manner to fracturing job. To study the fracking potential of a particular formation, along with data required for MEM, rock Brittleness properties, which govern fracture kinematic Properties (initiation, propagation, closure, toughness) should be studied as well.

To do so, we used Well logs to create (FMEM) to predict fracking potential. Brittleness was extracted from the Geomechanical and Mineralogical analysis. In the next step, we showed Total Organic Carbon (TOC) present in the matrix affects stiffness and frack ability of rocks. (TOC) Obtained from Log Based analysis was calibrated with TOC from Laboratory experiments on core Samples. The constructed FMEM revealed how changes in pore pressure, in-situ stress properties, and physiochemical of the shale could hugely influence the drilling operations in the field. The Constructed FMEM revealed sweet spots for Fracking from the field, which will be an input of paramount importance in planning phases of well which will have an immense impact on Future Deviated Drilling and Hydraulic Fracturing, studies.
\end{abstract}

Index Terms-Fracture mechanical earth model, wellbore stability, brittleness.

\section{INTRODUCTION}

Mechanical earth modelling is a representation of

Manuscript received February 5, 2018; revised March 30, 2018.

Rehan Ali Mohammed is with Department of Petroleum Engineering, University of North Dakota, Grand Forks, North Dakota, ND 58203 USA (e-mail: rehanali2731@gmail.com).

Seyedalireza Khatibi is with University of North Dakota, Grand Forks, North Dakota, 58203 USA (e-mail: seyedalireza.khatibi@und.edu).

Mehdi Ostadhassan is with University of North Dakota, Grand Forks, ND, USA. (e-mail: mehdi.ostadhassan@engr.und.edu).

Azadeh Aghajanpour is with Curtin University, Sarawak (e-mail: Azadehaghajanpour@gmail.com).

Alexeyev Alan is with University of North Dakota, Grand Forks, North Dakota,58203, USA (e-mail: aalexeyev@uh.edu). mechanical rock properties of the reservoir, pore pressure and in-situ stresses from Well logs [1]. Many operators were severely impacted from Non-Productive Time (NPT) due to the stuck pipe, tight hole and other well bore instability issues [2]. Instability issues happen to be a part of drilling operations, which can be avoided if the proper geomechanical study of the formation being drilled is done before planning phase [3]. Such task requires geophysical well log data to estimate pore pressure, in-situ stresses, rock strength and elastic properties of the formation to create MEM. The next step is to calculate Fracture Kinematic properties to construct Fracture Mechanical Earth Model (FMEM). FMEM investigates the zones of high potential for fracture placement. The two key candidates for investigating fracturing potential of rock is brittleness and ductility. Hydraulic Fracturing Potential is the ability of the rock to respond to massive fracture network by maximizing stimulated reservoir volume [4]. The key factors to evaluate fracturing potential of a particular formation requires in-depth study of Geomechanical, Petro physical, Mineralogical including Fracture Kinematics properties. Characterizing Brittleness of shale reservoirs is highly challenging mostly when dealing with wells, which have no acoustic and shear slowness data. The objectives of the workflow is to create models to study the elastic nature of the formation and then compare the result with mineralogy and rock strength that can predict brittleness index. The total organic content of the field was investigated using Laboratory Experiments on Core samples with Rock-Eval, which were compared to results from Log Data. Brittleness Alone is not enough to characterize the Frack-ability of Unconventional Shale Reservoirs Jin [3].

\section{Methodology}

Mechanical Earth Modelling is a log based Methodology to predict mechanical behavior, In-situ stresses and safe mud weight window. Input data needed to build MEM includes wireline logs, seismic data, image log data, Pore pressure, stresses, and laboratory test data from experiments on core samples. A series of empirical correlations were used to extract geomechanical properties from log data. Mechanical earth modeling workflow is as follow:

1) Study the formation lithology, and calculate shale volume (V-shale) using Gamma Ray logs.

2) Calculating rock strength, elastic and mechanical properties such as Young's Modulus, Poisson's Ratio, UCS (Uniaxial compressive strength), Biot's Coefficient, Tensile Strength, Friction Angle using log data. 
3) Estimating Vertical stress $\left(S_{V}\right)$ using Density logs.

4) Estimating Pore pressure from Acoustic slowness logs and calibrating with (Modular Dynamic Tester) MDT data.

5) Determining the maximum and minimum horizontal stresses using empirical correlations, which can be calibrated to leak off test (LOT) Data, if available.

6) Finally calculating Kick Mud weight, Break Out mud weight, Loss Mud weight and Break down Mud weight to predict Safe mud weight window. Fracture Mechanical Earth Model Workflow is as below in Fig. 1.

7) Next step is estimating the brittleness index from elastic and rock strength properties.

8) Estimating mineralogical Brittleness Index and compare with Elastic and Mechanical Brittleness Index.

9) Calculating TOC using Log based empirical correlations and calibrating with Laboratory experiments on Core Samples.

10) Calculate Maturity index using Petro physical logs.

11) Calculate Fracture Toughness and Fracture Index.

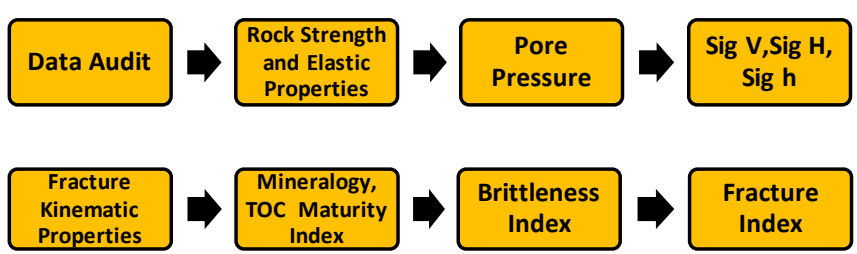

Fig. 1. Fracture mechanical earth model workflow.

\section{A. Geomechanical Properties}

The next step is the calculation of Geomechanical properties of the formation from well log data, which includes elastic properties, rock strength properties, in-situ Stresses and pore Pressure.

Elastic Properties: Elastic properties of rocks is divided into Static and Dynamic. Dynamic Properties such as Poisson's Ratio and Dynamic Young's Modulus are calculated from empirical correlations related to Acoustic, shear wave velocities obtained from Compressional sonic, and Shear.

$$
E_{\text {dynamic }}=\left[\frac{\rho}{\Delta t_{s}^{2}}\right]\left[\frac{3 \Delta t_{s}^{2}-4 \Delta t_{p}^{2}}{\Delta t_{S}^{2}-\Delta t_{p}^{2}}\right]
$$

where $\Delta t_{p}$ and $\Delta t_{s}$ is Acoustic and Shear slowness, $\rho$ is Bulk Density.

Young's Modulus, Static:

$$
E_{\text {static }}=0.414 * E_{\text {dyn }}-1.05
$$

\section{Poisson's Ratio:}

$$
(v)=0.5\left[\frac{\Delta t_{s}^{2}-2 \Delta t_{p}^{2}}{\Delta t_{s}^{2}-\Delta t_{p}^{2}}\right]
$$

where $\Delta t_{p}$ and $\Delta t_{s}$ are compressional and shear sonic logs (us/ft).

Shear modulus: also known as rigidity modulus; it shows the resistance to stress deformations.

$$
G_{d y n}=\frac{E_{d y n}}{2(1+v)}
$$

Bulk modulus and shear modulus is used when dealing with low-frequency data.

$$
K_{d y n}=\frac{E_{d y n}}{3(1-2 v)}
$$

Rock strength Properties: Log Based Modelling is the efficient way to extract reservoir properties in the absence of core data [5]. As core samples were not available for rock strength measurement, UCS was calculated from empirical correlation, which uses Acoustic slowness (DT) , as the well was from shale formation we use empirical correlation by Bradford [6].

$$
U C S=2.28+4.1089 * E_{\text {stat }}
$$

where UCS is unconfined compressive strength (MPa), $E_{\text {stat }}$ is the static Young's Modulus calculated using Equation (2).

Tensile Strength is $1 / 10^{\text {th }}$ of UCS.

Friction Angle (FANG): FANG is calculated using Plumb [7] empirical correlations, which is related to porosity and shale volume.

$$
\varphi=26.5-37.4\left(1-\phi-V_{\text {shale }}\right)+62.1\left(1-\phi-V_{\text {shale }}\right)^{2}
$$

where $\phi$ is the Neutron Porosity, $V_{\text {shale }}$ is the shale volume that is calculated using equation (8).

$\mathbf{V}_{\text {shale: }}$ Volume of shale is calculated using maximum and minimum values of Gamma ray.

$$
V_{S H A L E}=\left(G R-G R_{M I N}\right) /\left(G R_{M A X}-G R_{M I N}\right)
$$

where $G R_{M I N}$ and $G R_{M A X}$ are minimum and maximum values of Gamma Ray Log.

Pore Pressure: To calculate pore pressure we use Eaton's method, which uses acousticslowness log.

$$
P_{p}=O B G-\left(O B G-P_{h y d}\right)\left(\frac{\Delta T_{n}}{\Delta T_{l o g}}\right)^{3}
$$

where $O B G$ is overburden stress gradient, $P_{\text {hyd }}$ is hydrostatic pore pressure gradient and log refer to normal and measured values of $\Delta \mathrm{T}$ at each depth. $\Delta T_{n}$ is the Normal Compaction Trend plotted against $\Delta T$.

In-situ Stresses: In-situ stresses are categorized as $S_{V}$ (Overburden stress) $S_{H}$ and $S_{h}$ (Maximum and Minimum Horizontal Stresses). Direction of Horizontal stresses can be determined from Formation Micro Imager Log. Poroelastic theory can be used to find the magnitude [2], which can be calibrated with Leak off test and Mini Frack test data.

$$
\begin{gathered}
S_{V}=\rho g h \\
S_{h}=\frac{v}{1-v}\left(S_{v}-\alpha P_{P}\right)+\alpha P_{P}+\frac{E \varepsilon_{x}}{1-v^{2}}+\frac{v E \varepsilon_{y}}{1-v^{2}} \\
S_{H}=\frac{v}{1-v}\left(S_{v}-\alpha P_{P}\right)+\alpha P_{P}+\frac{E \varepsilon_{y}}{1-v^{2}}+\frac{v E \varepsilon_{x}}{1-v^{2}}
\end{gathered}
$$

where $\rho$ is density, $g$ is acceleration due to Gravity, $v$ is Poisson's ratio, $P_{P}$ is the Pore pressure, $\varepsilon_{x}$ and $\varepsilon_{y}$ are parameters corresponding to tectonic strains coefficients in the field. The Biot's coefficient $\alpha$ is assumed as 1 .

The workflow discussed earlier is used to construct MEM. Fig. 2 shows MEM of a well in Bakken Shale of Williston Basin. The First Track Shows Depth in (ft.). Track 2 shows the Gamma Ray Log (GAPI), Track 3 Shows the Density (ROHZ) in (gm/cc) and Neutron Porosity (NPHI). Track 4 shows compressional and shear slowness Logs in (us/ft.). Track 5 Shows the static and dynamic young's modulus (GPa) 
extracted from compressional and shear sonic logs. Track 6 shows Poisson's ratio and Biot's coefficient. Track 7 represents Rock strength properties such as Friction Angle (Degrees), Rock Strength (UCS) MPa, calculated from Bradford's Equation (6), and Tensile Strength. UCS values obtained from log based empirical correlation can be calibrated with UCS from core test data to get better results. Track 8 shows Pore pressure estimated from Eaton's Method, Maximum and Minimum Horizontal Stresses (MPa) and Vertical Overburden stress (MPa). Pore pressure can be calibrated with MDT Data to get accurate results. It can be seen that the magnitude of stress is in the order of $\left(S_{V}>S_{H}>S_{h}\right)$ which is a normal stress regime. Track 10 shows the Safe Mud weight window.

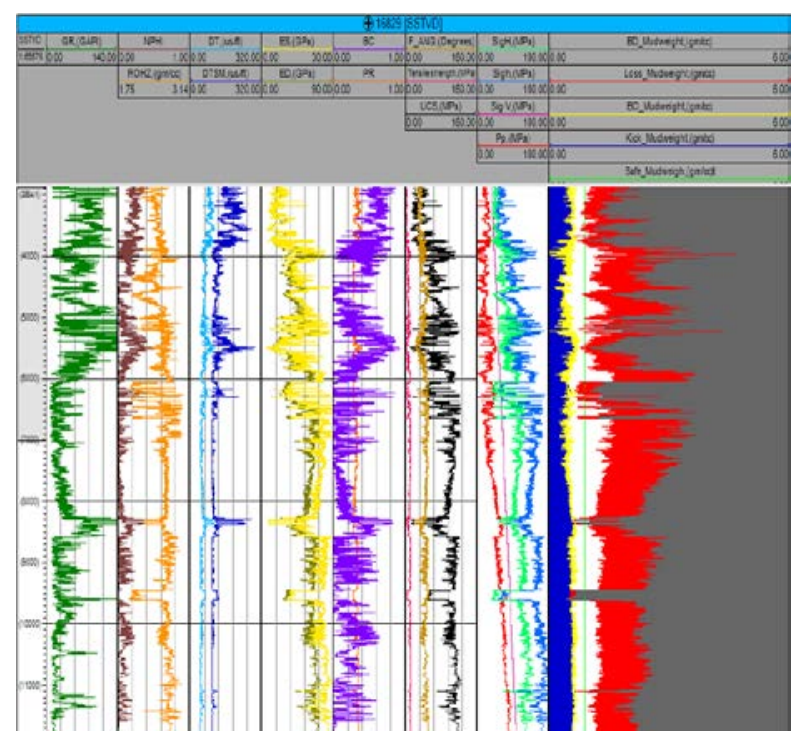

Fig. 2. 1D mechanical earth model of well 16829.


Fig. 3. The concept of safe mud weight window [6].

The fluorescent line is the predicted safe mud weight window using MEM. Fig. 3 illustrates the concept of Safe Mud Weight Window. Rock failure happens mostly due to strength anisotropy and zones of weak parallel bedding [8]. Track 10 shows the four different mud weight profiles, Kick Mud weight, Breakout Mud weight, Loss Mud weight, Breakdown Mud weight. If a mud weight used is less than the pore pressure gradient of the formation results in Influx of formation fluids into the well bore, which results in a kick. If mud weight is less than the breakout pressures gradient will lead to shear failure of bore hole integrity. If excessive mud weight is used can cause mud loss into the formation. If mud weight is increased further beyond the loss mud weight gradient, will results in initiation of fractures Fig. 3. A safe mud weight window of $0.9 \mathrm{~g} / \mathrm{cc}$ is proposed. It is seen that there is mud loss at certain depths, which can be controlled by surface parameters.

\section{B. Fracture Mechanical Earth Modelling}

Fracture Mechanical Earth Modelling is the idea of predicting Fracturing potential by use of petrophysical well logs and Laboratory test Data. FMEM investigates the elastic and geomechanical behavior of the formation and compares the results with formation mineralogy to identify sweet spots for Hydraulic Fracturing. Input logs from mechanical earth model are used to extract rock strength properties such as (Brittleness, Toughness, Total Organic Carbon, Fracture Porosity, Maturity Index, Fracture Index, etc.). The concept of measuring rock brittleness is not a new concept to Oil and Gas Industry. Rock brittleness is the ability of the rock to shear with little stress. Brittleness of rock is a function of Rock Mineral content, Strength, Fluid in the pores, Organic Content, texture, and stresses acting on the rock. However, there is not any standard method to estimate exact brittleness of rock. Mineralogical brittleness index is the most accurate of all formulations to calculate brittleness index. Brittleness index formulations show different values for the same specimen.

\section{Brittleness}

It is understood that formations, which show high brittleness, are key candidates of Fracturing. There is no universally accepted scale to quantify brittleness and ductility [5]. A formation such as a limestone and dolomite act as fracture indicators but when compared with shales rock brittleness serves as a fracture barrier due to low fracture gradient in shales. Brittleness log identifies the key spots of high brittleness based on rock strength properties around the well bore. It is impossible to have the same values of brittleness estimated from different methods because they are based on different Physical Mechanisms. Brittle rock happens to fail when the stress acting on the rock exceeds the rock strength. Brittleness is also used to evaluate Drillability of rock [9]. Estimation of Brittleness is a key for successive hydraulic fracturing in shales [10].

\section{Geomechanical Brittleness}

Estimation of Geomechanical Brittleness Index requires elastic and geomechanical properties derived from well logs. There are many ways of estimating the brittleness available in the literature. The most common is the geomechanical brittleness obtained from compressional and shear wave velocities.

Jin [4] formulated correlation for Calculating Brittleness using Young's Modulus and Poisson's Ratio derived from Sonic and Density logs.

$$
B I=\left(\frac{B I_{E}+B I_{V}}{2}\right) * 100
$$

Where $B I_{E}, B I_{V}$ are the brittleness Index derived from Young's Modulus and Poisson's Ratio.

$$
B I_{E}=\left(E-E_{\min }\right) /\left(E_{\max }-E_{\min }\right)
$$

Where $B I_{E}$ is Brittleness from Young's Modulus $E_{\max }$ and $E_{\text {min }}$ are Maximum and minimum values of Young's Modulus. $E$ is calculated using equation (2). 


$$
B I_{V}=\left(v-v_{\max }\right) /\left(v_{\min }-v_{\max }\right)
$$

where $B I_{V}$ is Brittleness from Poisson's Ratio, $v_{\max } v_{\min }$ are Maximum and minimum values of Young's Modulus. $v$ ic calculated using equation (3).

The log plots of brittleness estimated from geomechanical and elastic properties are seen in Fig. 4, which shows the similar log trend.



Fig. 4. Brittleness estimated from elastic and geomechanical properties.

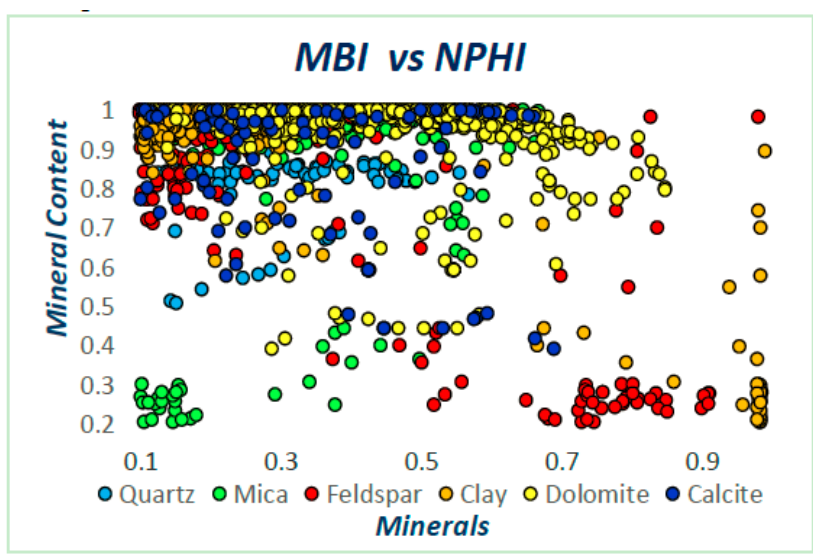

Fig. 5. Crossplot of mineral content versus neutron porosity.

Fig. 5 illustrates the crossplot of mineralogical brittleness versus porosity, which shows formation is less porous and exhibit high brittleness. Fig. 6 high show high brittleness corresponds to low Poisson's ratio.

\section{Young's Modolous vs PR}

Poisson's Ratio

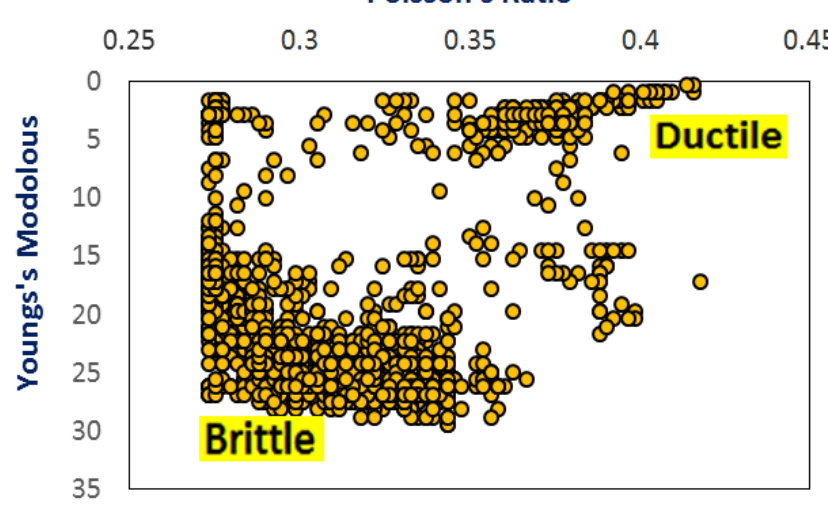

Fig. 6. Cross plot of young's modulus versus poisson's ratio showing the brittle and ductile regions.

\section{E. The Mineralogical Brittleness}

Wireline Logs such as Gamma Ray, Neutron Porosity, Shear, Compressional slowness, and Resistivity logs are used for stratigraphic characterization of pay zones. Log signatures from the logs are not the accurate representation of pay zone strata, which requires in depth study of mineralogy and geomechanics. There are many methods of estimating the brittleness available in the literature. The most accurate till date is mineralogical brittleness. Jarvie [11], Wang and Gale [12] developed formulations to estimate Brittleness from Mineral Proportion data:

$$
B \mathrm{I}=\frac{\mathrm{QZ}+\text { Car }}{\mathrm{Qz}+\text { Car+Fels }+ \text { Clay }+\mathrm{TOC}}
$$

where $B I$ is brittleness index, Oz, Car, Fels, Clay, TOC are the percentage of Quartz, Carbonate, Feldspar, Clay and Total Organic Carbon.

Fig. 7 shows the mineralogy extracted from resistivity logs. Fig. 8 and The crossplot in the Fig. 9 illustrates mineral content versus depth. The zone on the plot from a depth of (10541-10590) ft shows high clay content due to the presence of shale formation.



Fig. 7. Mineralogical analysis of formation from deep and shallow resistivity logs. 




Fig. 8. The proportion of minerals.

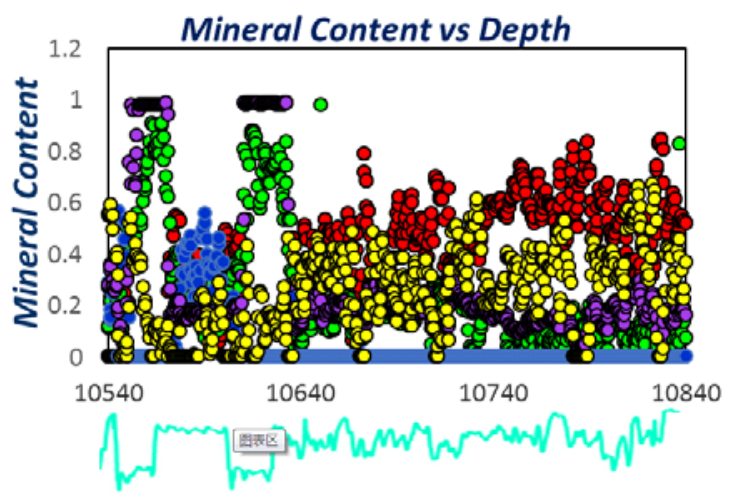

1. Depth(ft) 2. Mineralogical BI

- Dolomite - Calcite o Feldspar • Quartz o Clay O Mica

Fig. 9. Mineral content versus depth.

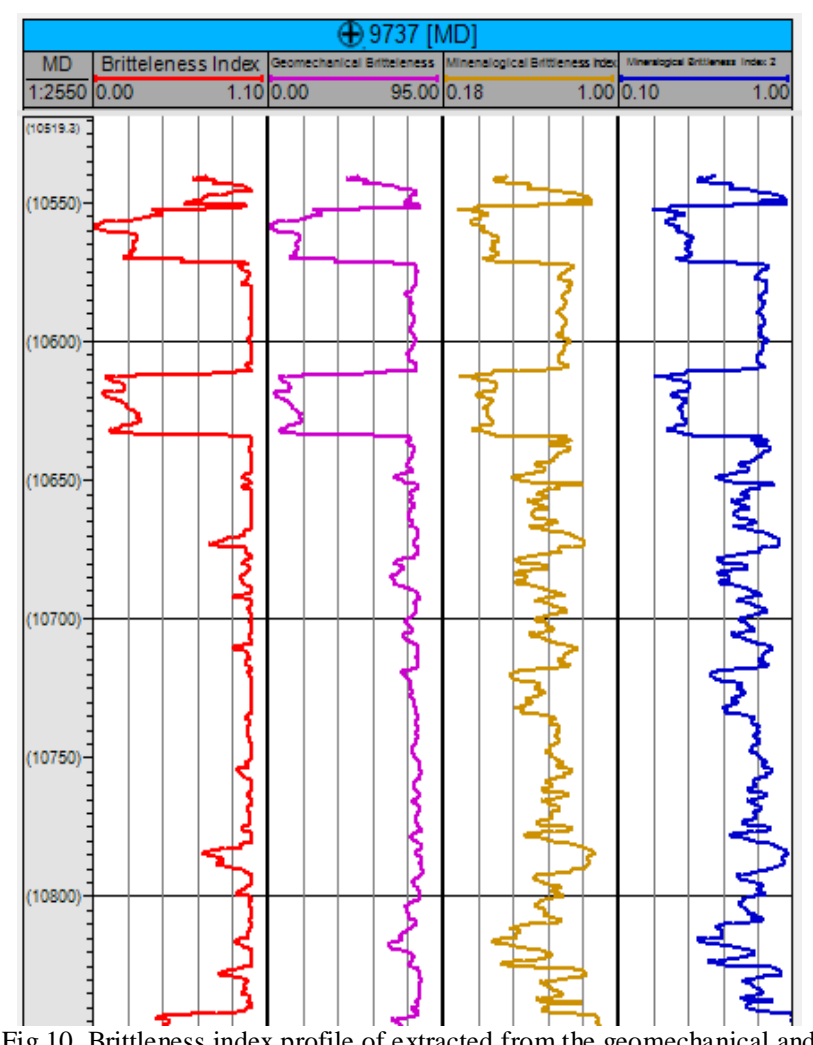

Fig.10. Brittleness index profile of extracted from the geomechanical and mineralogical analysis.
The log plots in the Fig. 10 show the brittleness calculated from log Geomechanical properties and mineralogical proportion, which shows the similar log trend.

Fracture Toughness Index: Fracture Toughness is the ability of the rock to resist crack propagation [13]. Fracture Toughness index is a measure of the energy required to shear the rock. Atkinson [14] proposed equation to calculate Fracture Toughness from Elastic Properties and Rock Strength data.

$$
T_{I}=\left(\frac{\sigma^{2}}{2 * E}\right) * 100
$$

where $\sigma$ is Uniaxial Compressive Strength (MPa) which is calculated using equation (6), E is Young's Modulus (MPa) which is calculated using (2), $T_{I}$ is toughness Index.

Fracture Porosity: Fracture Porosity can be determined from Sonic and Neutron Log. Porosity from Neutron log comprises of Matrix and Fracture porosity while sonic log represents only Matrix Porosity. A correlation developed by Chacon [15] was used to evaluate fracture porosity.

$$
\phi_{f}=\phi_{\text {Neu }}-\phi_{\text {Son }}
$$

where $\phi_{f}$ is fracture porosity, $\phi_{N e u}$ is Neutron Porosity and $\phi_{\text {Son }}$ is Sonic Porosity.

Fracability Index: Fracability Index is the ability of the rock to create fracture network when stimulated. Soliman and Alzahabi [16] developed a correlation for estimating Fracture Index.

$$
\begin{aligned}
F I=0.871 *( & \left(\left(\frac{E}{1-v^{2}}\right)-\left(\frac{E}{1-v^{2}}\right)_{\min }\right) /\left(\left(\frac{E}{1-v^{2}}\right)_{\max }\right. \\
& -\left(\frac{E}{1-v^{2}}\right)_{\min }
\end{aligned}
$$

where $\left(\frac{E}{1-v^{2}}\right)_{\max },\left(\frac{E}{1-v^{2}}\right)_{\min }$ are maximum and minimum Plane strains in the reservoir.

Thermal Maturity: It's difficult to measure the organic content of rock by use of Mechanical experimenting equipment's [17]. Thermal Maturity of the formation can be obtained from the Density and Sonic Porosity Logs using Labani and Rezaee [18] method. Maturity of rock will have a significant impact on fracture propagation [19].

$$
\begin{aligned}
L M I_{\phi} & =\left(\phi_{L o g}-\phi_{\max }\right) /\left(\phi_{\min }-\phi_{\max }\right) \\
L M I_{\rho} & =\left(\rho_{\text {log }}-\rho_{\max }\right) /\left(\rho_{\min }-\rho_{\max }\right) \\
L M I & =\left(L M I_{\phi}+L M I_{\rho}\right) / 2
\end{aligned}
$$

where $L M I_{\phi}, L M I_{\rho}$ is Log based Maturity Index from Porosity and Density Logs, $\phi_{\text {Log }}, \phi_{\text {min }}, \phi_{\text {max }}$, $\rho_{\text {log }}, \rho_{\text {min }}, \rho_{\text {max }}$ Are maximum and minimum values log.

Total Organic Carbon: Source rock contains a high amount of organic matter, which can be identified from log signatures from Gamma and Resistivity Logs. TOC content in the rock is associated with ductile nature of the rock. High TOC results in low brittleness. TOC content is helpful in locating pay zones and sweet spots for fracture placement. TOC Content of the formation can be studied from laboratory experiments on core samples. TABLE I shows the TOC content of few wells in the field from Rock-Eval, 
approximately 60-70 mg per sample were used for Rock-Eval pyrolysis. The instrument used was the Rock-Eval 6 analyzer, commercialized by Vinci Technologies in France. Based on studies of 59 shale samples of Bakken shale a correlation was developed by Schmoker and Hester [20] to estimate TOC content from Density Logs.

$$
\operatorname{TOC}(w t . \%)=\left(\frac{154.479}{\rho_{b}}\right)-57.261
$$

where $\rho_{b}$ is the Bulk Density from density logs.

TABLE I: TOTAL ORGANIC CARBON (WT \%) FROM A LABORTORY EXPERIMENT ON CORE SAMPLES FROM THE SAME FIELD

\begin{tabular}{c|cccc}
\hline $\begin{array}{c}\text { Well } \\
\text { No }\end{array}$ & $\begin{array}{c}\text { Core } \\
\text { Sample } \\
\text { Depth }\end{array}$ & $\begin{array}{c}\text { TOC } \\
\text { (Wt\%) }\end{array}$ & $\begin{array}{c}\text { VRo-Eq (\%) } \\
\text { Duvernay } \\
\text { Model }\end{array}$ & $\begin{array}{c}\text { VRo-Eq (\%) } \\
\text { Barnett } \\
\text { Model }\end{array}$ \\
\hline 23285 & 10553 & 14.93 & 0.8252 & 0.904 \\
20457 & 11199 & 16.36 & 0.8848 & 0.976 \\
19472 & 5483 & 24.71 & 0.39 & 0.38 \\
17699 & 8325 & 16.27 & 0.53 & 0.54 \\
21928 & 9886 & 15.76 & 0.59 & 0.62 \\
12162 & 10725.5 & 0.86 & 0.86 & 0.94 \\
\hline
\end{tabular}

Log Plots in the above Fig. 11 shows the Physiochemical properties of the formation, at a depth of 10700-10900 ft., it can be seen that high Gamma ray values correspond to the large volume of clay content, consequently high TOC content. Zones with high TOC exhibit low brittleness. Table I shows the result Roc-Eval analysis on core samples for measuring the TOC ranging between $6-20 \%$.

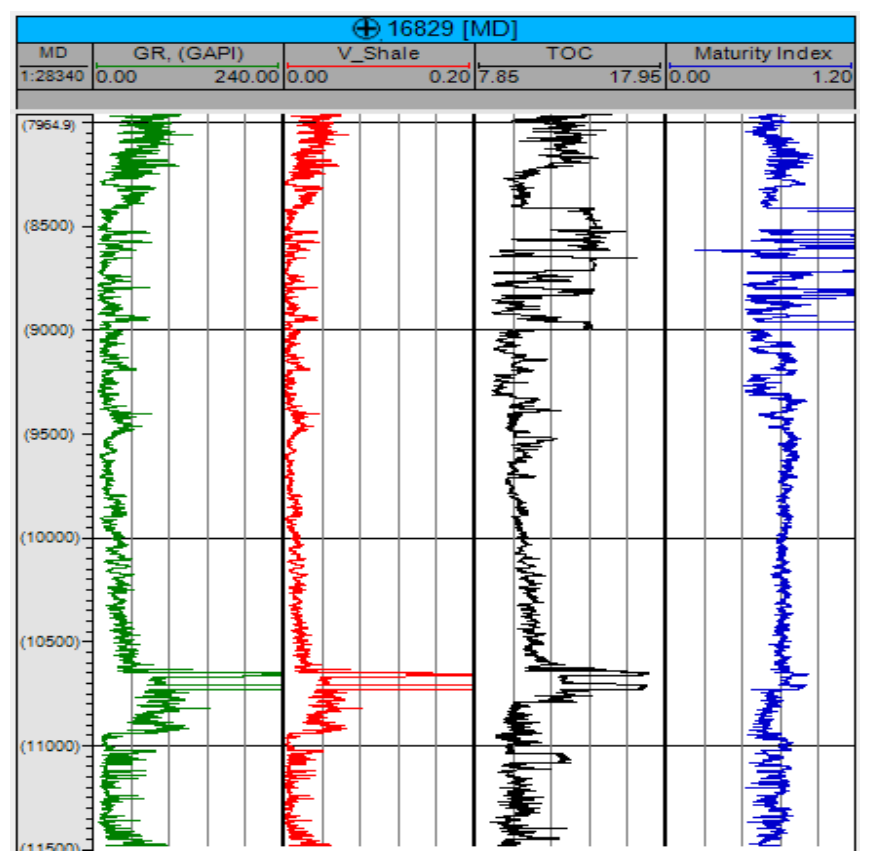

Fig. 11. Log plots are showing the organic properties of the formation.

Fig. 12. Shows the elastic and rock strength properties. Track 2 shows the static modulus, which represents the stiffness of the formation. Track 3 shows Poisson's ratio calculated from sonic and density logs corresponds to low poisons Ratio represents the formation strength. It is seen that high static modulus relates to low poisons ratio. Formations with High brittleness creates effective fracture Network. The reason for the abrupt changes, in the elastic and rock strength properties depth of $10600-10900 \mathrm{ft}$ is due to the presence of shale formation (Bakken Shale) and tight reservoir (Three Forks).

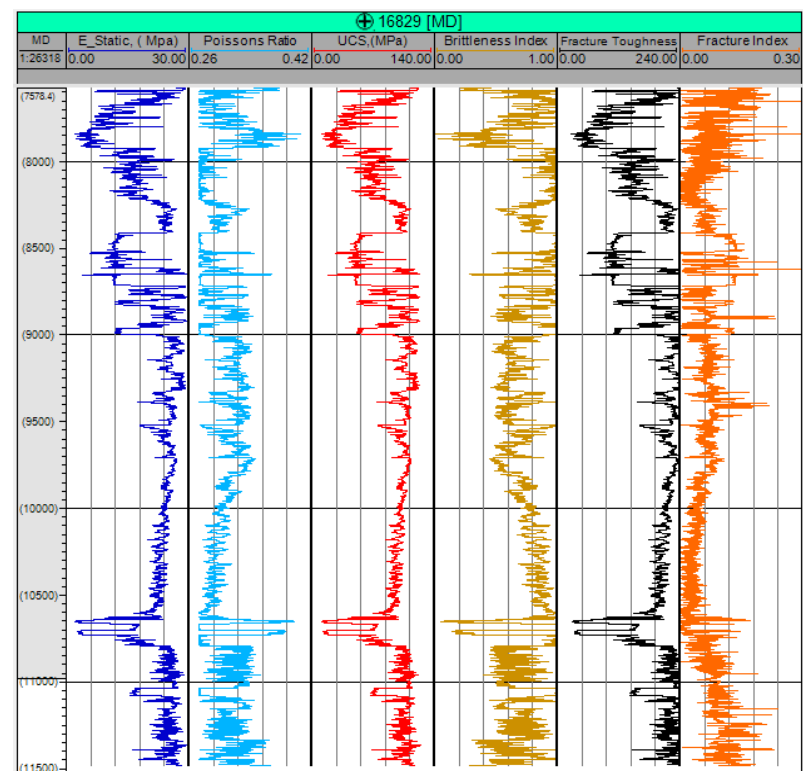

Fig. 12. Log plots showing the rock strength properties from FMEM.

The Fracture Mechanical Model (FMEM) is a log-based methodology to estimate fracturing potential of a particular formation, which involves extracting Petrophysical, Geomechanical and Fracture Kinematic Properties. One of the most useful logs for estimating formation strength properties is Acoustic and Shear Sonic Logs. The Geomechanical properties such as Poisson's Ratio and Young's Modulus are derived from the Compressional and Shear Sonic Logs, which show the stiffness of the formation. FMEM uses properties derived from mechanical earth model as explained in the above workflow. Fig. 13 illustrates the geomechanical and rock strength properties.



Fig. 13. Fracture mechanical earth model (FMEM).

The First track is the depth in $\mathrm{ft}$. Track 2 shows the Gamma Ray (GAPI). Track 3 shows the Volume of shale calculated from Gama Ray Log. Track 4 shows the Static Young's modulus calculated from Compressional and shear sonic Logs. Track 5 shows Poisson's Ratio from sonic and Density Logs. Track 6 shows Uniaxial compressive strength (UCS) in Mpa, estimated from Bradford's Equation. Track 7 shows the Total Organic Content in $(\mathrm{Wt} \%)$ values ranging between 6-20\%. Track 8 shows the Log Based Maturation index 
estimated using Labani and Rezaee [4] using Sonic and Density Logs. Track 9 shows the brittleness Index. Track 10 shows the fracture toughness in (MPa), track 10 shows Fracture porosity extracted from density and sonic logs. Track 11 shows Fracture Index estimated using equation (19). The zone from the depth of (10600-10900) is a Tight shale formation called Bakken shale and the reservoir called Three Forks.

From the FMEM it is seen that there is steep variation in log signatures at a depth of (10600-10900) ft., which is due to the presence of presence of Bakken shale. The Young's Modulus and Poisson's ratio at the reservoir showed high and low values. Fig.10 shows the brittleness estimated from geomechanical and mineralogical analysis. Log signatures from the plots showed similar trends. The results obtained from Laboratory experiment on core samples showed the presence of High TOC content in the shale formation. The maturity Index showed the same pattern. The formation showed high brittleness, which can be effective in creating good fracture Network.

\section{RESULTS AND CONCLUSIONS}

This study was intended to understand the concept of fracture mechanical earth model to predict fracturing potential of a well in Williston basin. Results from the Mechanical earth model showed the elastic behavior of formation. A normal stress Regime was observed in the well with some zones of mud loss. It is essential to study geomechanical and Mineralogical behavior including Fracture kinematics for a successful fracture Job. The concept of safe mud weight window prediction was examined, and zones of instabilities were established. A safe mud weight of $0.9 \mathrm{~g} / \mathrm{cc}$ was suggested to avoid instability issues while drilling. Fracture Mechanical earth model to study the fracturing potential revealed the zones of high brittleness and high TOC, which are sweet spots for fracture placement. Rock elastic and geomechanical properties including mineralogy were investigated. Mineralogical analysis showed that the formation is highly dolomitic due to the presence of high dolomite content, which is the primary cause of high brittleness. Results from this study will be useful in deviated drilling and Hydraulic Fracturing operation in the field. The input from this study is also helpful in planning phases of the well which will prevent hazardous accidents and unplanned well maintenance cost.

\section{ACKNOWLEDGMENT}

There was no funding available for this work. The authors thank Seyedalireza Khatibi for his work on Total organic carbon content extraction from Laboratory experiments on core samples.

\section{REFERENCES}

[1] A. Azadeh, S. H. Fallahzadeh, S. Khatibi, M. M. Hossain, and A. Kadkhodaie, "Full waveform acoustic data as an aid in reducing uncertainty of mud window design in the absence of leak-off test," Journal of Natural Gas Science and Engineering, vol. 45, pp. 786-796, 2017.

[2] P. Richard, S. Edwards, G. Pidcock, D. Lee, and B. Stacey, The Mechanical Earth Model Concept and Its Application to High-Risk Well Construction Projects, 2000.
[3] X. C. Jin and S. N. Shah, "A practical petrophysical approach for brittleness prediction from porosity and sonic logging in shale reservoirs," in Proc. SPE Annual Technical Conference and Exhibition, in Amsterdam, Netherlands, October 27-29, 2014.

[4] A. Alexeyev, M. Ostadhassan, R. A. Mohammed, B. Bubach, and S. Khatibi, "Well log based geomechanical and petrophysical analysis of the bakken formation," in Proc. 51 $1^{\text {st }}$ US Rock Mechanics Symposium, in San Francisco, California, USA, vol. 28, June 2017.

[5] X. C. Jin, S. N. Shah, J. C. Rorgiers, and B. Zhang, "Fracability evaluation in shale reservoirs-an integrated petrophysics and geomechanics approach," in Proc. SPE Hydraulic Fracturing Technology Conference, in Woodland, Texas, USA, February 4-6, 2014.

[6] I. D. R. Bradford, J. Fuller, J. Thompson, and T. R. Walsgrove, "Benefits of assessing the solids production risk in a north sea reservoir using elastoplastic modeling," in Proc. SPE/ISRM Eurock, in Trondheim, Norway, July 8-10, 1998.

[7] R. A. Plumb, "Influence of composition and texture on the failure properties of clastic rocks" in Proc. SPE.ISRAM Eurock, in Delft, The Netherlands, August 29-31, 1994.

[8] J. Lang, S. L. Li, and J. C. Zhang, "Wellbore stability and real-time surveillance for deepwater drilling to weak bedding planes and depleted reservoirs," in Proc. SPE/IADC Drilling Conference and Exhibition, in Amsterdam, The Netherlands, March 1-3, 2011.

[9] V. Hucka and B. Das, "Brittleness determination of rock by different methods,” International Journal of Rock Mechanics. Min. Sci., vol. 11, pp. 389-392, November 1974.

[10] R. P. Altamar and K. Marfurt, "Mineralogy-based brittleness prediction from surface seismic data: Application to the barnett shale. interpretation,” vol. 2, no. 4, November 2014.

[11] D. M. Jarvie, R. J. Hill, T. E. Ruble, and R. M. Pollastro "Unconventional shale-gas systems: The Mississippian Barnett Shale of north-central Texas as one model for thermogenic shale-gas assessment,” AAPG Bulletin, vol. 91, pp. 475-499, 2007.

[12] F. P. Wang and J. F. Gale, "Screening criteria for shale-gas systems," Gulf Coast Association of Geological Societies Transactions, vol. 59, pp. 779-793.

[13] B. Tiryaki, "Evaluation of the indirect measures of rock brittleness and fracture toughness in rock cutting," Journal of South African Mining and Metallurgy, June 2006.

[14] T. Atkinson, V. B. Cassapi, and R. N. Singh, "Assessment of Abrasive wear resistance potential in rock excavation machinery," International Journal of Mining and Geological Engineering, vol 4, issue 2, pp 151-163, Jan. 1986.

[15] A. Chacon and D. Tiab, "Effects of stress on fracture properties of naturally fractured reservoirs," in Proc. SPE Latin American and Caribbean Petroleum Engineering Conference, in Buenos Aires, Argentina, April 15-18, 2007.

[16] A. A. Soliman, M. Y. AlQahtani, G. D. Bateman, R. M. Asquith, and G. Jan, "Fracturability index maps for fracture placement in shale plays," Hydraulic Fracturing Journal, Jan. 2015.

[17] C. Li, M. Ostadhassan, T. Gentzis, K. Liu, and S. Khatibi, "In-situ nano-mechanical characterization of organic matter in shale,” in Proc. Annual TSOOP Conference, in Calgary, Canada, Sep. 21-27, 2017.

[18] M. M. Labani and R. Rezaee, "Thermal maturity estimation of gas shale layers from conventional well log data: A case study from kockatea shale and Caryuginia formation of Perth Basin, Australia,” in Proc. SPE Asia Pacific Oil and Gas Conference and Exhibition, in Perth, Australia, October 22-24, 2012.

[19] S. Khatibi, M. Ostadhassan, D. Tuschel, T. Gentzis, C. X. Li, K. Q. Liu, and H. Carvajal-Ortiz, "Understanding kerogen mechanical properties using raman spectroscopy,” in Proc. TSOP Conference, in Calgary, Canada, Sep. 21-27, 2017.

[20] C. H. James and W. S. Timothy, "Organic carbon in bakken formation,” United States Portion of Williston Basin, AAPG Bulletin, vol. 67, 1983.

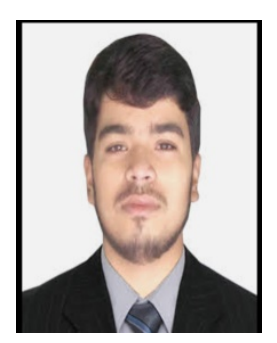

Rehan Ali Mohammed currently works as Drilling Fluids and Rock Physics Lab assistant at the University of North Dakota. He is currently a graduate student in Petroleum Engineering at the University of North Dakota, Grand Forks North Dakota, USA. He completed his bachelor's in petroleum engineeringin (2015) from Jawaharlal Nehru Technological University, Hyderabad, India. His research interests are rock physics and geomechanics. 


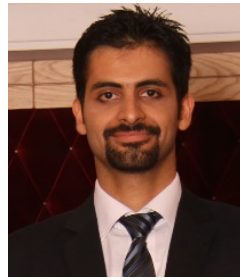

Seyedalireza Khatibi was born in Iran in 1989.

He got his bachelor and master degree in the field of petroleum engineering at Amirkabir University (Polytechnique Tehran) in 2011 and 2013, respectively. Seyedalireza is now a Ph.D student at the University of North Dakota, USA. He started working as a geoscientist (Geophysics section) in an oil company working in South Pars Gas Field for less than four years and though away from school his enthusiasm was not dampened and published some paper on Geomechanics.

Mr. Khatibi is a student member of SPE (Society of Petroleum Engineers), AGU (American Geophysical Union), and also vice president of SEG (Society of Exploration Geophysicists) student chapter of UND.

Mehdi Ostadhassan is an assistant professor in the Department of Petroleum Engineering at the University of North Dakota. Mehdi joined the petroleum department in Aug. 2013. Before starting his appointment at UND, he worked in the industry for several years as a petroleum geophysicist in various capacities. He also served as the energy division manager for the Atlantic Int. The operation, a UAE based company over a year. Mehdi's research is an integration of petroleum geoscience and engineering and is mainly focused on the characterization of the unconventional reservoirs
Azadeh Aghajanpour received her bachelors and master degrees from the Amirkabir University of Technology in 2012 and 2014, respectively. She is currently a Ph.D student at Curtin University Malaysia and working on drilling and Geomechanics.

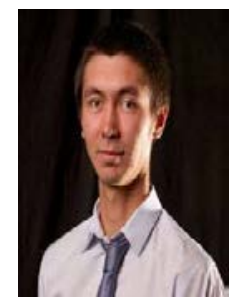

Alan Alexeyev is a current graduate student at the University of North Dakota pursuing his master's degree in petroleum engineering. His current project includes working with well logging data for geomodelling and petrophysical analysis. Alan is looking forward to joining a dynamic oil industry in the near future to apply the knowledge gained in the universities in the real world and to contribute to this industry through a continuing learning, research, practice, effective communication, and collaboration. As an active SPE member, he has attended multiple petroleum conferences and exhibitions around the world. Alan got his B.S in petroleum engineering at University of Wyoming and BS in mathematics from the University of Houston. 